\title{
SCRATCH'S THIRD BODY
}

\section{VIDEO TALKS BACK TO TELEVISION}

\author{
Leo Goldsmith \\ New York University \\ Tisch School of the Arts \\ Department of Cinema Studies \\ 721 Broadway, 6th floor \\ NY NY 10003 \\ United States of America \\ llg246@nyu.edu
}

\begin{abstract}
Emerging in the UK in the 1980s, Scratch Video established a paradoxical union of mass-media critique, Left-wing politics, and music-video and advertising aesthetics with its use of moving-image appropriation in the medium of videotape. Enabled by innovative professional and consumer video technologies, artists like George Barber, The Gorilla Tapes, and Sandra Goldbacher and Kim Flitcroft deployed a style characterized by the rapid sampling and manipulation of dissociated images drawn from broadcast television. Inspired by the cut-up methods of William Burroughs and the audio sampling practiced by contemporary black American musicians, these artists developed strategies for intervening in the audiovisual archive of television and disseminating its images in new contexts: in galleries and nightclubs, and on home video. Reconceptualizing video's 'body,' Scratch's appropriation of televisual images of the human form imagined a new hybrid image of the post-industrial body, a 'third body' representing a new convergence of human and machine.
\end{abstract}

Keywords: scratch video; TV sampling/remixing; British video art; appropriation; found footage; videoprocessing; interactive spectatorship; posthumanism.

\section{Appropriation, Remix, Sampling}

From the NSA to Facebook, animated GIFs to fan edits and supercuts, practices of appropriation occupy a central, but distinctly ambiguous position in contemporary culture that's not simply widespread but serves as a sort of default aesthetic mode of internet culture, as Lev Manovich, ${ }^{1}$ among others, have claimed. At the same time as mediasampling and remixing have become more commonplace (in the form of YouTube supercuts and fan-culture memes), practices such as piracy, torrenting, and file-sharing have come under increased scrutiny and restriction by the content industry and government bodies. In contemporary internet culture, appropriation is everywhere: both in social media content-sharing and in the practices of government and corporate bodies to manage and monitor our activities online. In effect, practices of sampling and reuse have mutated from radical modernist aesthetic strategies to common activities embedded in our hypernetworked everyday lives. 


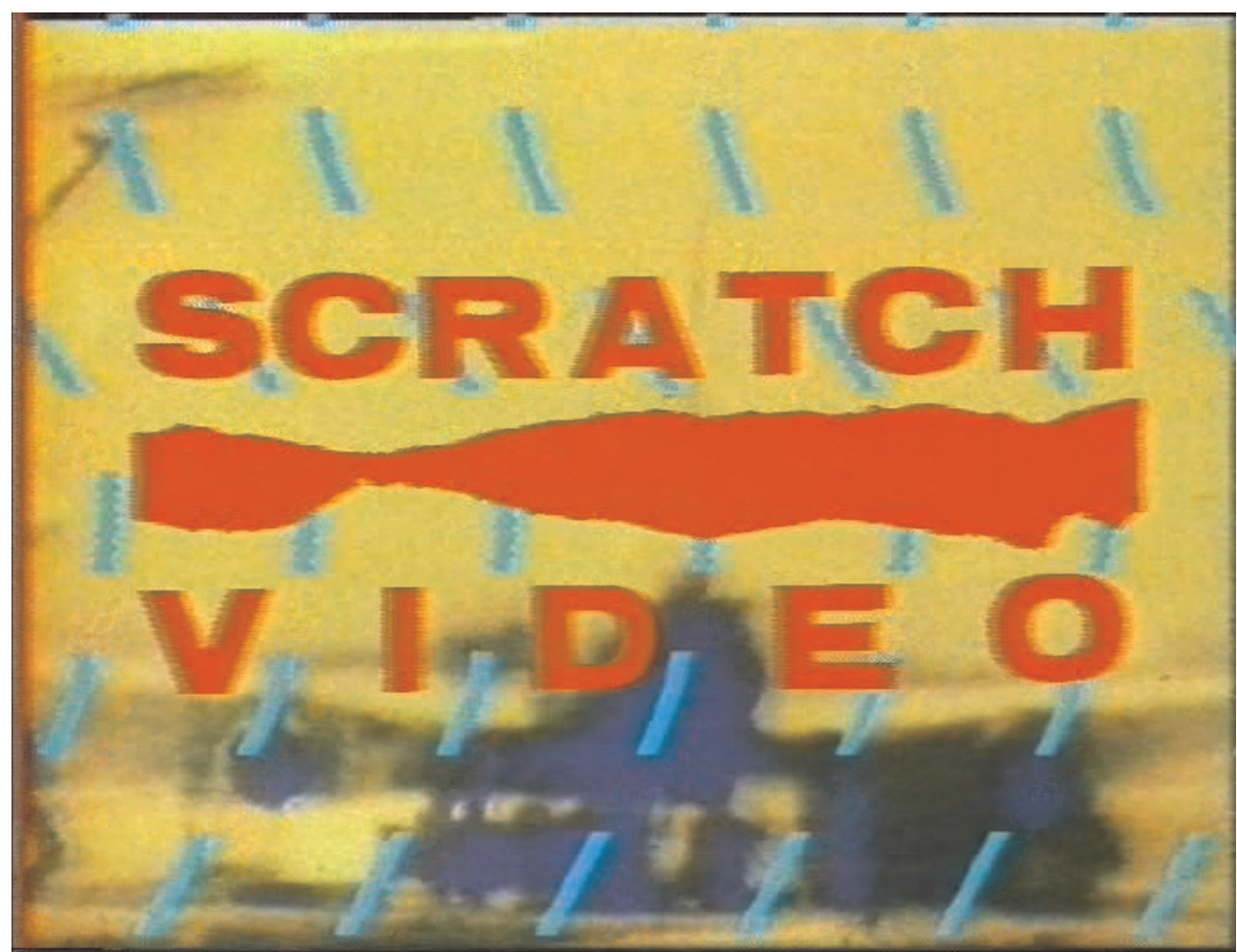

Photo 1. Scratch logo, The Greatest Hits of Scratch Video, Vol. 1 (1985)

In order to better understand the recent history and mutation of the aesthetics and practices of appropriation, I would like to examine an earlier moment in the history of moving-image appropriation, one in which these strategies were enabled by the emergence of professional and consumer technologies of videotape. Scratch Video, a loosely defined, somewhat short-lived, but no less influential video movement that arose in the United Kingdom in the early 1980s, offers some insight into the ambivalent development of pre-Internet styles of moving-image sampling and remixing. Born at the intersection of recently established art-school video production programs, urban dance clubs, and post-punk music subcultures, Scratch situated itself at the nexus of a number of distinct but related media, including video art, music, and performance. But its primary foil was broadcast television and via the medium of videotape and new technologies to edit and manipulate it, Scratch refashioned TV's images into an unstable union of mass-media critique and music-video/ advertising aesthetics.

By using television images as its raw material, Scratch positioned itself, and video more generally, as the medium for a more dynamic, more interactive mode of image-consumption, and even a more networked mode of viewership—as the group Gorilla Tapes later put it, Scratch was a way of "talk[ing] back to television."2 Enabled by the development of innovative professional and consumer video technologies (including home video systems, video synthesizers, flexible editing platforms), artists like Gorilla Tapes, George Barber, and Sandra Goldbacher and Kim Flitcroft deployed a style characterized by the rapid sampling, editing, and manipulation of dissociated images drawn from video archives and broadcast television. Exploiting this newly available battery of tools, Scratch Video artists warped, composited, windowed, posterized, keyed, colorized, and superimposed these images, exploring uncharted aesthetic terrain that in many ways anticipates, and has strongly influenced, the types of image-manipulation made possible by today's digital image software and practiced by the pirates and professionals, VJs and YouTubers alike.

And yet, while the work of Scratch Video frequently displayed a satirical bent, lampooning contemporary political figures (such as Margaret Thatcher and Ronald Reagan) and hacking television's own modes of address, its own fast and 


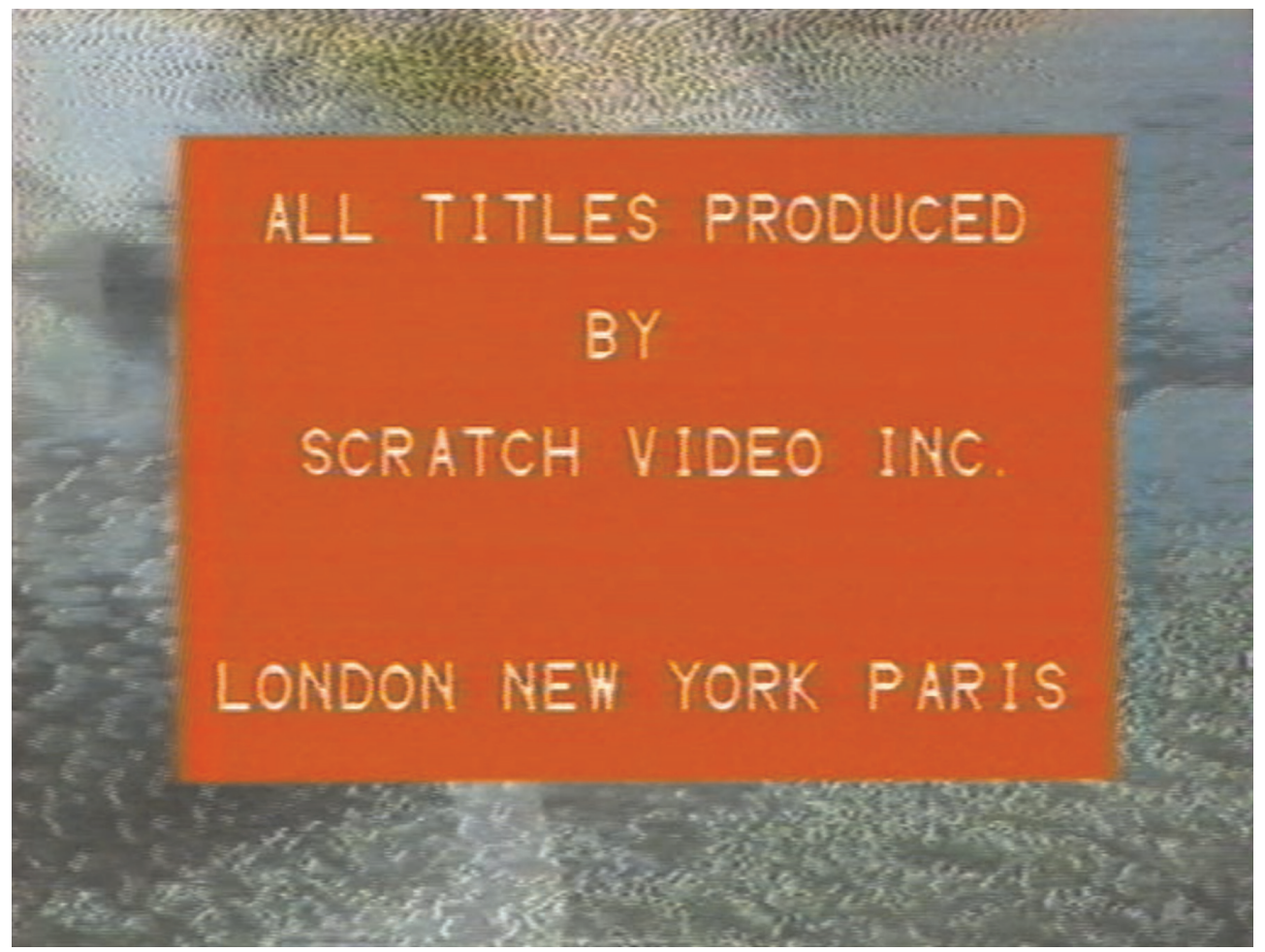

Photo 2. Scratch logo, The Greatest Hits of Scratch Video, Vol. 1 (1985)

colourful aesthetic strategies made it a seductive — and therefore suspicious — style, itself ripe for appropriation by television advertisers and commercial media.

Scratch Video courts this ambivalence, highlighting some of the paradoxes inherent in a new media landscape marked by interactivity and participation, one with both utopian and dystopian connotations, in which blurs boundaries between the professional and the amateur, the mainstream and the underground, the commercial and the politically engaged. Here, I will argue that Scratch Video's reuse and remixing of television's representations of the human body, recomposed and re-engineered through new technologies of video editing and processing, reveals an image of a new spectatorial relationship with media, embodied by a new kind of producer/consumer.

Video 1. Tilt (dir. George Barber, 1984). Go to the online version of this article to watch it.

\section{Influences and Antecedents}

Scratch's strategies of reuse and remix are part of a long history of appropriation in the arts in the twentieth century. The modernist tropes of collage and montage are especially evident in Scratch, and in other media forms of a period newly invigorated by the accessibility of new technologies of appropriation and manipulation. Simon Reynolds, writing about the late 1970 s and early 1980 s from the perspective of popular music, writes:

Those postpunk years from 1978 to 1984 saw the systematic ransacking of twentieth-century modernist art and literature. The entire postpunk period looks like an attempt to replay virtually every major modernist theme technique. ${ }^{3}$ 
While postpunk bands like Test Dept and Cabaret Voltaire would pay explicit homage to Soviet Constructivism and Dada, Scratch artists were also quick to pay tribute to their forebears. Nick Cope, who has written extensively on his work with Scratch video, explicitly cites as important influences the détournement strategies of the Situationist International and the cut/up and fold-in methods of collage developed by Brion Gysin and William Burroughs while they were in London in the 1960s. ${ }^{4}$ Exploring these strategies using both written text and audiotape, Gysin and Burroughs, in their book The Third Mind, advocated a hybrid form of authorship in which two consciousnesses could be held at once, an aesthetic program for the juxtaposition of discordant elements to form new unities and release latent, even revolutionary potentialities.

Some years after the mid-eighties heyday of Scratch, Gorilla Tapes (Gavin Hodge, Jon Dovey, and Tim Morrison) would pay tribute to the World War II-era artist John Heartfield in their experimental documentary feature Zygosis, which they made for Channel Four television in 1991. Heartfield's works constituted a rare political challenge to Hitler's rule through the absurdist collage and juxtaposition which the film's title likens to a process of conjugation among gametes.

In the early 1960s, the content and apparatus of the television became the targets of interventions by US-based artists like Wolf Vostell (Sun in Your Head, 1963) and Nam June Paik (Magnet TV, 1965), and a decade later in the UK, artist David Hall created his seven TV interruptions, which were broadcast on Scottish television in $1971 .{ }^{5}$ Perhaps most importantly, the work of video artist Dara Birnbaum, which was first exhibited at the Institute for Contemporary Art in London in 1983, proved an immediate influence on the rhythmic pirate aesthetic of Scratch. Such antecedents and influences establish an aggressive, media-interventionist stance with regard to mass media, and especially television, that Scratch would, in part, take up later, though with significant differences.

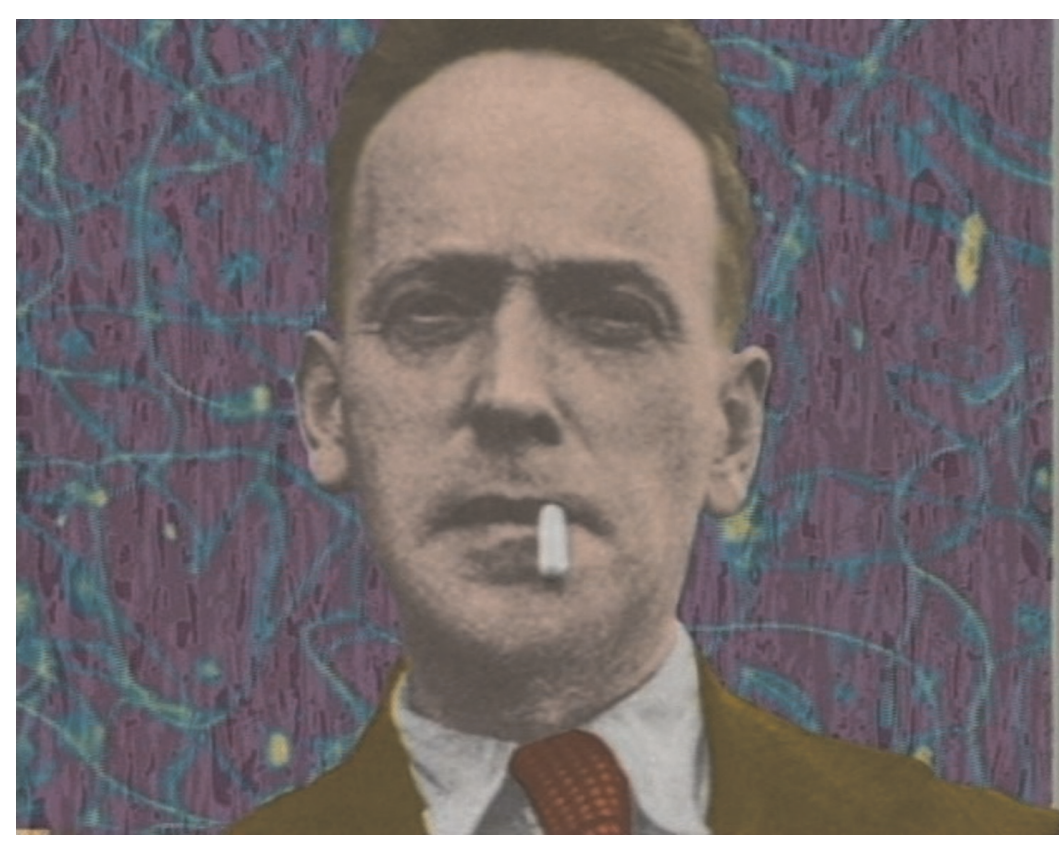

Photo 3. Zygosis, directed by Gavin Hodge, 1991, Icarus Films.

4 See Nicholas D. Cope, Northern Industrial Scratch: The History and Contexts of a Visual Music Practice, University of Sunderland, Art, Design and Media, June 2012, p. 55.

5 While it did not use appropriated images, Hall's landmark work was nonetheless seen as an explicit antecedent of Scratch Video, having been placed alongside self-identified Scratch artists like Barber, Cope, and Goldbacher and Flitcroft in Subverting Television, a touring three-part programme of British video works curated by Mark Wilcox, Michael O'Pray, and Alex Graham for the Film and Video Umbrella and supported with funding from the Arts Council of England in 1985. 
L. Goldsmith, Scratch's Third Body

As the name suggests, Scratch Video drew most immediately upon the aesthetic of new black popular music forms: the cut-and-mix music emerging from Caribbean enclaves in London, and especially the turntable-scratching of New York hip hop. According to artist George Barber, the term 'Scratch Video' was coined by journalist Pat Sweeney, offering the comparison with New York's emerging hip hop scene-and possibly conveying the myth Scratch artists were a collection of urban youth populations of colour manipulating images with jury-rigged VCRs. ${ }^{6}$ In fact, the technologies that made Scratch possible were much more expensive and exclusive, available only to art school students and professionals. Barber attributes the development of the style to the availability of particular technologies in art schools at that time: the Sony Series V editing suite, which allowed for rapid editing, and video processing tools, like the Quantel Paintbox, which allowed for advanced mixing and image-manipulation. ${ }^{7}$ These tools enabled artists to work, effectively, in real time, performing live alterations and juxtapositions that ordinarily would previously have taken hours of editing time.

This artful and kinetic manipulation of images as well as sounds enabled the Scratch aesthetic to form new hybridizations of video art and dance music. Its facility with generating effects quickly and with a great deal of chance, combined with audio sampling computers, made the work a close audiovisual approximation of the kinds of fast cutting and distorting work already becoming familiar from hip hop. Underscoring this impression was the fact that Scratch was exhibited, not in art contexts, but in musical ones. In 1985 and 1986, respectively, Barber produced two home-video collections - The Greatest Hits of Scratch Video, Vol. 1 and 2, which he distributed himself to record shops like Rough Trade. $^{8}$

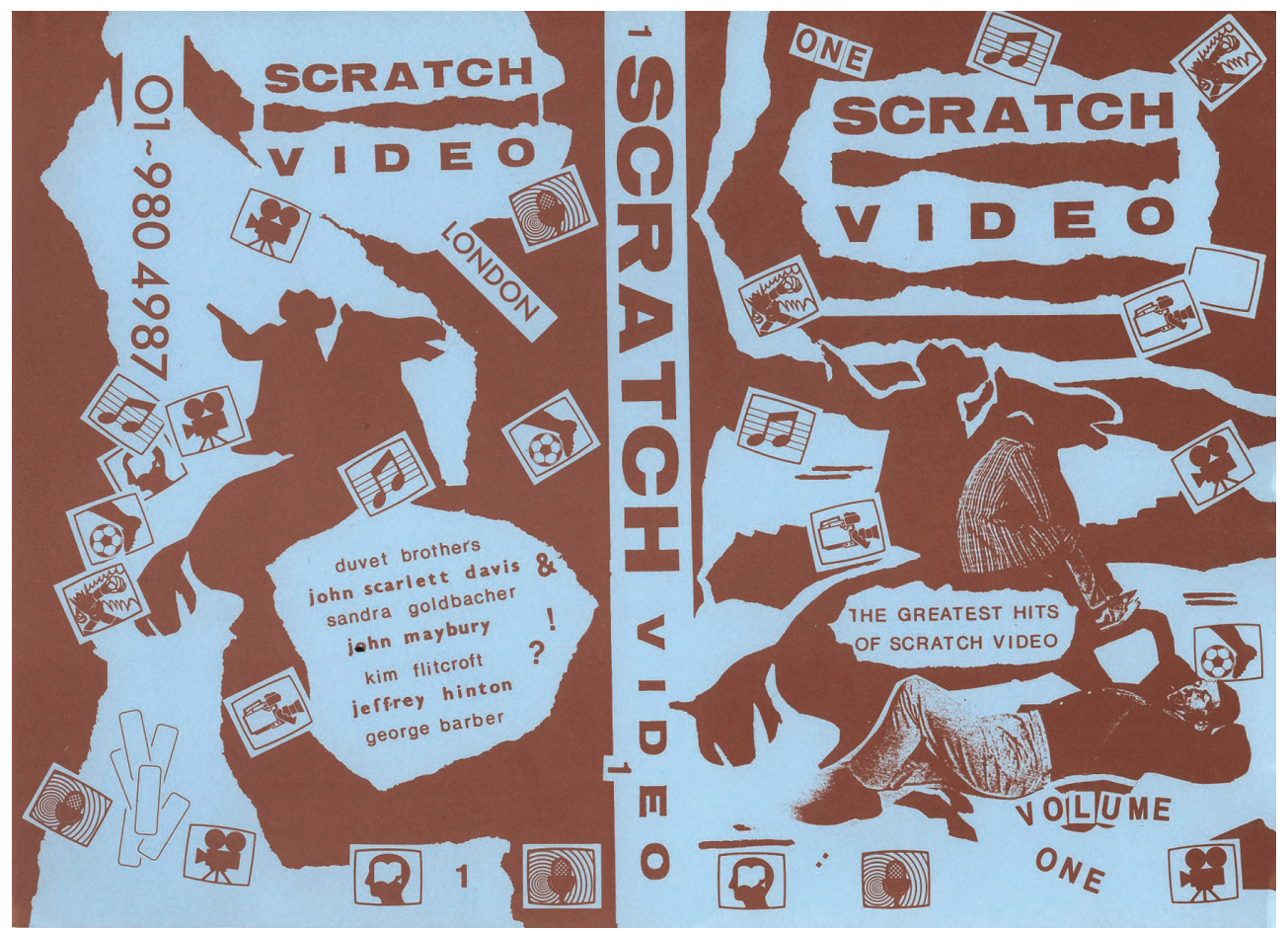

Photo 4. The Greatest Hits of Scratch Video, Vol. 1, VHS cover art. Courtesy of REWIND: Artists' video in the 1970s and 80s.

6 Barber, "Scratch and After: edit suite technology and the determination of style in video art" in Philip Hayward, ed. Culture Technology and Creativity in the late twentieth century, John Libbey, 1990, p. 116.

7 Barber, "Scratch and After: edit suite technology and the determination of style in video art" in Philip Hayward, ed. Culture Technology and Creativity in the late twentieth century, John Libbey, 1990, p. 114. For more on the Quantel Paintbox, see Howard Weinberg, "TV Lab: Image-making Tools," in Kathy High, Sherry Miller Hocking, and Mona Jimenez, eds., The Emergence of Video Processing Tools: Television Becomes Unglued, Volume 1, Intellect, University of Chicago Press, 2014, p. 144. For more on the development of British video art alongside television production and other forms of artistic practice, see Sandy Nairn, "The Video Mix," in The Second Link: Viewpoints on Video in the Eighties, Walter Phillips Gallery, 1983, p. 21. 8 As Barber told me in conversation, he would also fulfill personal orders by delivering copies of the video on his bicycle. Interview with the author, March 2012. 
Similarly, Scratch artists made videos for or otherwise collaborated with post-industrial, post-punk bands like Cabaret Voltaire, This Heat, Psychic TV, and 23 Skidoo, who used audio-sampling in their work. Most importantly, Scratch video works were not shown in art galleries, but in music venues and nightclubs like The Fridge in Brixton, which was founded by Andrew Czezowski and Susan Carrington in 1981 only a few months after the Brixton riots, and which featured a video exhibition space and a 'video wall' - a bank of monitors playing multiple images — designed by Bruno de Florence. ${ }^{9}$ Between 1984 and 1988, the Duvet Brothers also toured Europe and the United States with a multi-screen projection performance set-up that included up to 25 television monitors. ${ }^{10}$

\subsection{The Loop and the Scratch}

In a cover feature for the alternative weekly magazine City Limits in October 1984, Andy Lippman described Scratch as:

hip hop video, image breakdancing, television does a body pop. Broadcast TV is scoured for arresting images and fed into video editing systems like shredding machines. The fusion of funk rhythms and visuals on collision course crumble original context. Reassurance and sweet reason, television's façade, disintegrate before your bombarded eyes. ${ }^{11}$

Here, the description of the loop and the scratch as assaultive affective experiences is instructive. Writing about the development of these techniques in black American music among artists like Kool Herc, Grandmaster Flash, and Mantronix, the writer and artist Kodwo Eshun describes the techniques of the scratch and the loop as key components of a kind of Afrofuturist technology: machinic strategies for generating new continuities, new points of connection between the medium and listener through media appropriation and manipulation. For Eshun, the scratch is a tool for defamiliarizing language and sound, and for dissolving and distorting the syntactical elements of an original audio work: "To scratch is to evolve the turntables into a tone generator, a defamiliarizer, a word-molecularizer. Skratchadelia isn't a rhythm so much as its wreckage made rhythmic." ${ }^{12}$ At the same time, the loop is a means of training the mind and body into synchronizing with new rhythms made from a synthetic continuity:

Looping the break tricks the ear into hearing a continuous beat. Each cycle slips out of memory as if the body refuses to realize that it's hearing the same beat every time. Each loop trains the obstinate body until it recognizes its endpoint. Bodies starts to remember the point when the beat loops back on itself. There's a psychoacoustics of rhythm: the big brain anticipates the cycle, gets into the groove, lives inside the tense present of the loop. The Breakbeat becomes a mnemonic. ${ }^{13}$

In aligning itself with hip-hop, Scratch Video thus positions itself as a similarly consumerist intervention in the television image, with magnetic videotape (instead of the turntable) as the instrument: a form of creative misuse that achieves similar effects through manipulations and repetitions of the surface, texture, and movement of the appropriated televisual image. For Barber, this was the point: meaning was secondary or even incidental to rhythm and fluidity. He writes, "this effect is the definitive 'look', the 'cutting edge' of Scratch, the technical ability to reawaken memories of a shot just gone, a process so fast that you enter oblivion or, paradoxically, a fast stasis—life between edits, video that keeps referring back and back to itself." 14

Video 2. 'Video Scratching' segment, Ear Say (Channel Four, 1984). Go to the online version of this article to watch it.

9 See http://www.deflorence.com/?p=283, last accessed on December $15^{\text {th }}, 2015$.

10 See http://www.duvetbrothers.com/multi.html, last accessed on December $15^{\text {th }}, 2015$.

11 Andy Lippman, "Scratch and Run," City Limits, 5-11, October 1984, p. 18.

12 Kodwo Eshun, More Brilliant Than the Sun, Quartet Books, 1998, p. 15.

13 Ibid 24.

14 Barber, "Scratch and After: edit suite technology and the determination of style in video art," p. 115. 


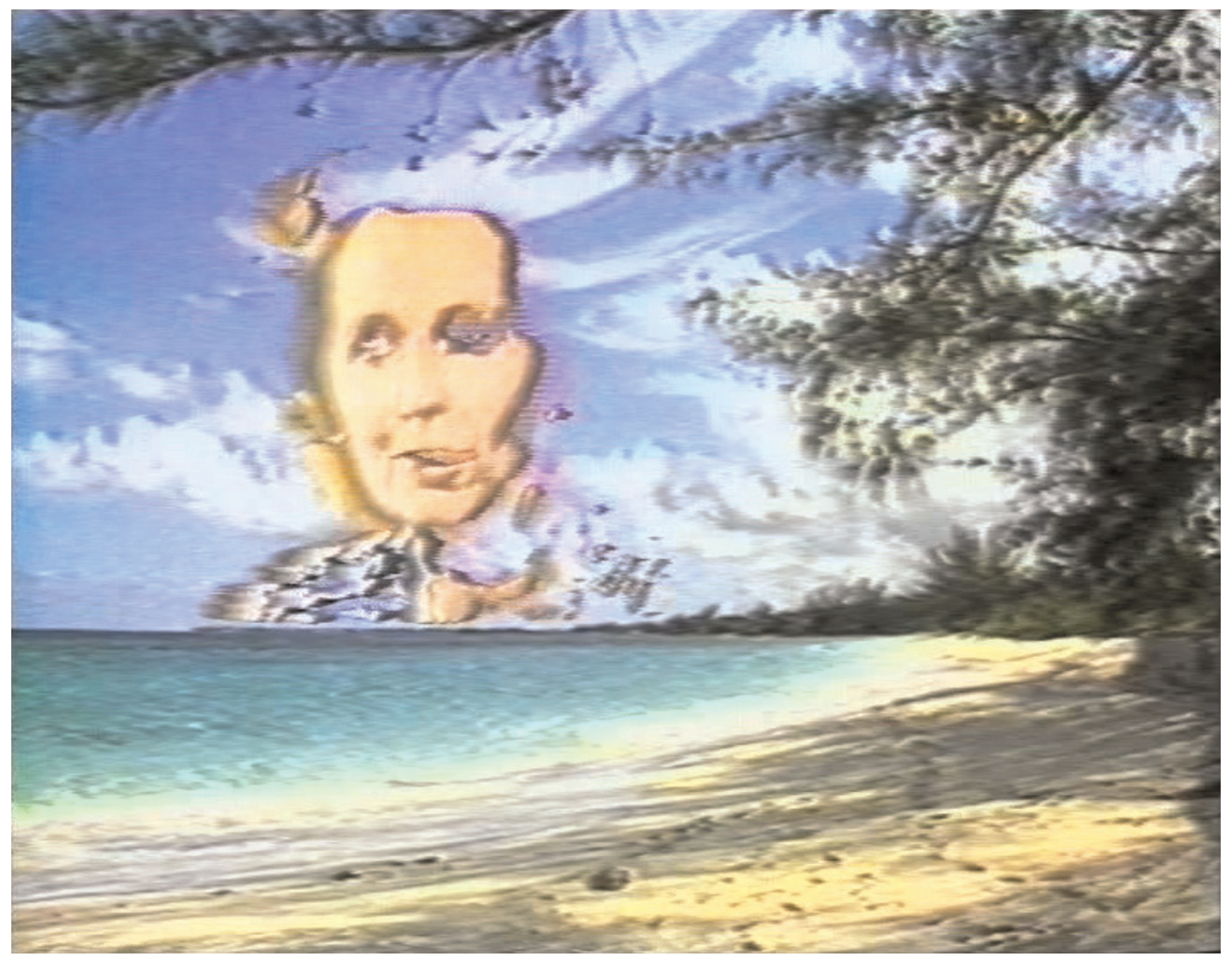

Photo 5. Till Death To Apartheid (dir. The Gorilla Tapes, 1985)

In combination with the techniques of looping and scratching imported from hip-hop, Scratch also deploys practices unique to video technologies, such as keying. Keying is a means of combining two images by knocking out areas of uniform colour: for example, a field of green in one image can be keyed out, and another image can be keyed into the image in its place. In Manovich's description of the term "An image created through keying presents a hybrid reality, composed of two different spaces." ${ }^{15}$ Or, indeed, two different bodies, unified into the semblance of one image. Keying, therefore, serves as a kind of optical analogy to the combinatory practices of scratching and looping, and together these practices compose Scratch's unique form of audiovisual collage.

In contrast to much found footage and archival film work that preceded it, Scratch's video appropriations were less interested in the careful analysis of archival images of the historical past than in their distortion and deformation. Scratch's assimilation of sound-manipulation strategies from hip-hop into visual media offer an approach to the recontextualization of images that is very different to those of modernism. These strategies suggest an approach to the image for different purposes than those of archival documentary, in which the source material's original meaning or historical context is usually maintained and explored in the new work. In Scratch, there is a much greater emphasis instead on more immediate aesthetics elements of the source material, such as colour, rhythm, or texture, and less of an interest in exploring the original images' original meanings. ${ }^{16}$ At the same time, by focusing less on historical

15 Lev Manovich, The Language of New Media, MIT Press, 2001, p. 150.

16 Here, a comparison with a slightly more commercial iteration of Scratch aesthetics is revealing. The music promo video for Paul Hardcastle's 1985 single "19" reinforces the song's general anti-war message with images taken from the 1984 ABC-produced documentary Vietnam Requiem, directed by Bill Couturie and Jonas McCord. The intersection of a message-driven song and historically specific images that the video recuts rhythmically in the style of Scratch generates a kind of discordance: whereas the song seems to demand a critique or reflection on the images' content, the style makes the images exciting and seductive, following the rhythmic hooks and loops of the single. 
images and more on contemporary ones-of the present, from news clips of Margaret Thatcher and Ronald Reagan to images of the 1984 Miners' Strike to ads for washing machines and cars-Scratch's images suggest a kind of mise-en-abime in which of-the-moment television images feed back into an endless cycle of reuse and manipulation. In this way, Scratch displays a somewhat ambivalent attitude to television and consumer culture more generally. On the one hand, its appropriation and manipulation of television's images suggests a form of commentary and critique intended to make visible the medium's own modes of manipulation and distortion, making malleable television's endless flow, which itself seems to mould and shape the present moment. But in Scratch's fast, propulsive rhythms, we often sense the ideal form of a slick, seductive editing style, one that either hopelessly or euphorically embeds in the feedback loop of audio-visual media consumption and creation.

\section{Two Modalities of Scratch?}

Video 3. Strike (dir. Enemy Within/John Hanlon, 1984). Go to the online version of this article to watch it.

While Chris Meigh-Andrews has identified two principle strains of Scratch Video-one more akin to agit-prop, the other of a more affective, less overtly political variety - the two modes are never very far apart. ${ }^{17}$ Both use the same seductive, jagged rhythms and video manipulation strategies, but Scratch's more engagé form used overtly political content in combination with aggressive editing and looping to burlesque the movements of the body, especially those of political figures, policemen, and soldiers, rendering them jerky robots or caricatures of fascist armies. These works use the scratch as a way of revealing the rigidity, dehumanization, and automatism underlying contemporary life. Indeed, the style of Scratch Video was perhaps uniquely adept to present (or re-present) the processes of dehumanization that were underway-in many ways, through the very technologies of representation themselves.

Video 4. Fuh Fuh (dir. The Duvet Brothers, 1984). Go to the online version of this article to watch it.

Images of consumption and the consumption of images: here, the video imagines an ingesting body whose image is itself fragmented and looped for a kind of visual ingestion and possibly regurgitation. The scratch deforms and segments the image both graphically and rhythmically, while the loop entraps the body onscreen in a spell, a routine gesture, a machinic motion. Imagining the consumption of images with that of ingestion, this short video by the Duvet Brothers offers a critique that fuses the consuming body onscreen with the consuming body of the spectator, both mechanized by moving-image technologies. Similarly, in Peter Savage's Tory Stories (1984), edited and looped images of Margaret Thatcher and several television advertising models assemble an image of a woman as a fragmented body, exploited and regulated by television advertising and broadcast newsemphasizing for both the female consumer and the female head of state the status of automatism, passivity, and objecthood.

What these videos suggest is a darker vision of the body of the consumer of the electronic image, depicting the human subject as the interpellated object of an increasingly regulatory, rather than liberating, television media. Even in the more affective, less politically overt works, like Kim Flitcroft and Suzanne Goldbacher's Night of 1000 Eyes (1984), video editing and processing increasingly mechanizes and dismembers the body, creating a menacing vision of the human form assaulted and swallowed up by video.

The slightly schizophrenic nature of Scratch Video as an object and a style seems intricately bound up in its nature: as agit-prop media-commentary and as a protean new aesthetic of fast-cutting excess and synthesized abundance. To 


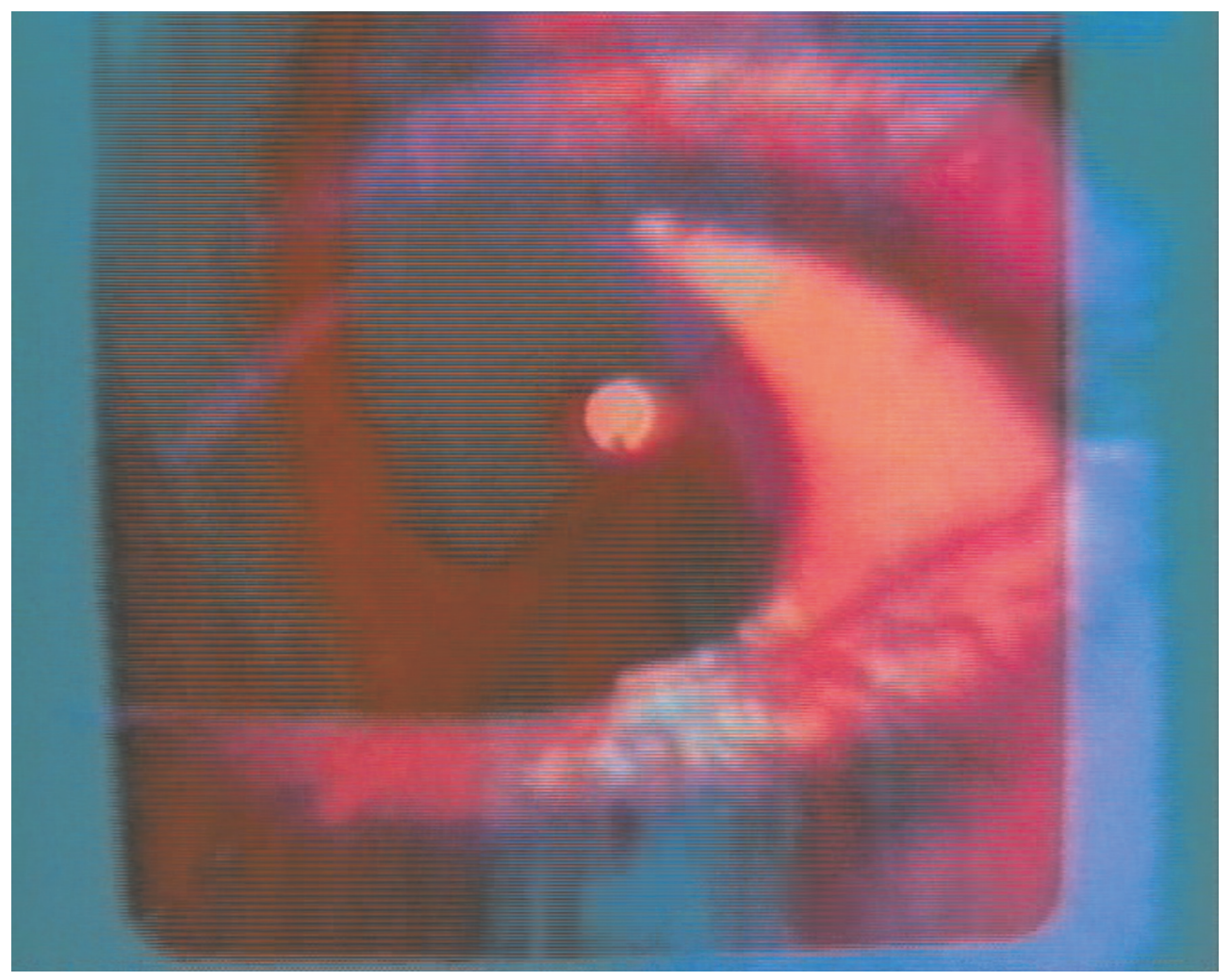

Photo 6. Night of 1000 Eyes (dir. Suzanne Goldbacher and Kim Flitcroft, 1984)

some commentators, this made Scratch deeply suspicious. The scholar and artist Catherine Elwes, who has written extensively about this period, noted in 1985 that "[s]ome artists are now trying to make direct social comments with scratch.. We are left wondering whether to debate the evils of unemployment or get up and dance." ${ }^{18}$ Early pop videos themselves were, after all, among the most innovative and experimental forms of advertising - a fact reinforced as Scratch's strategies were increasingly incorporated into the aesthetics of mainstream television, and some of Scratch's practitioners took on more commercial work. Later, in her book Video Art: A Guided Tour, Elwes also cites Barber as noting the similarities between Scratch's palette of video image manipulation tools and the aesthetics of station idents and nightly news broadcasts. Scratch's colourful, fluid futurism thus finds a curious new home in the very target of its satirical edge. ${ }^{19}$

However, as Sean Cubitt has argued, it is important to view video of this period, not as a monolith, but a leaky vessel, "one into which all manner of strange and unassimilable things may enter." ${ }^{20}$ If one of Scratch's aims was to use video to defamiliarize and distort the image of the body, it sought a similar effect on the body of video itself: tearing broadcast television from its original context in quite literal ways. Through its alternate exhibition and distribution practices, Scratch sought a more unstable context for video, rematerializing television's flow in other forms, other bodies: as an art installation, as a rock-club light-show, even as a commodity. Scratch video spread its images in ways that were impossible before the introduction of consumer video formats. In this sense, Scratch often seems less an artistic movement than a brand, appropriated and recirculated in a range of discourses and contexts. 


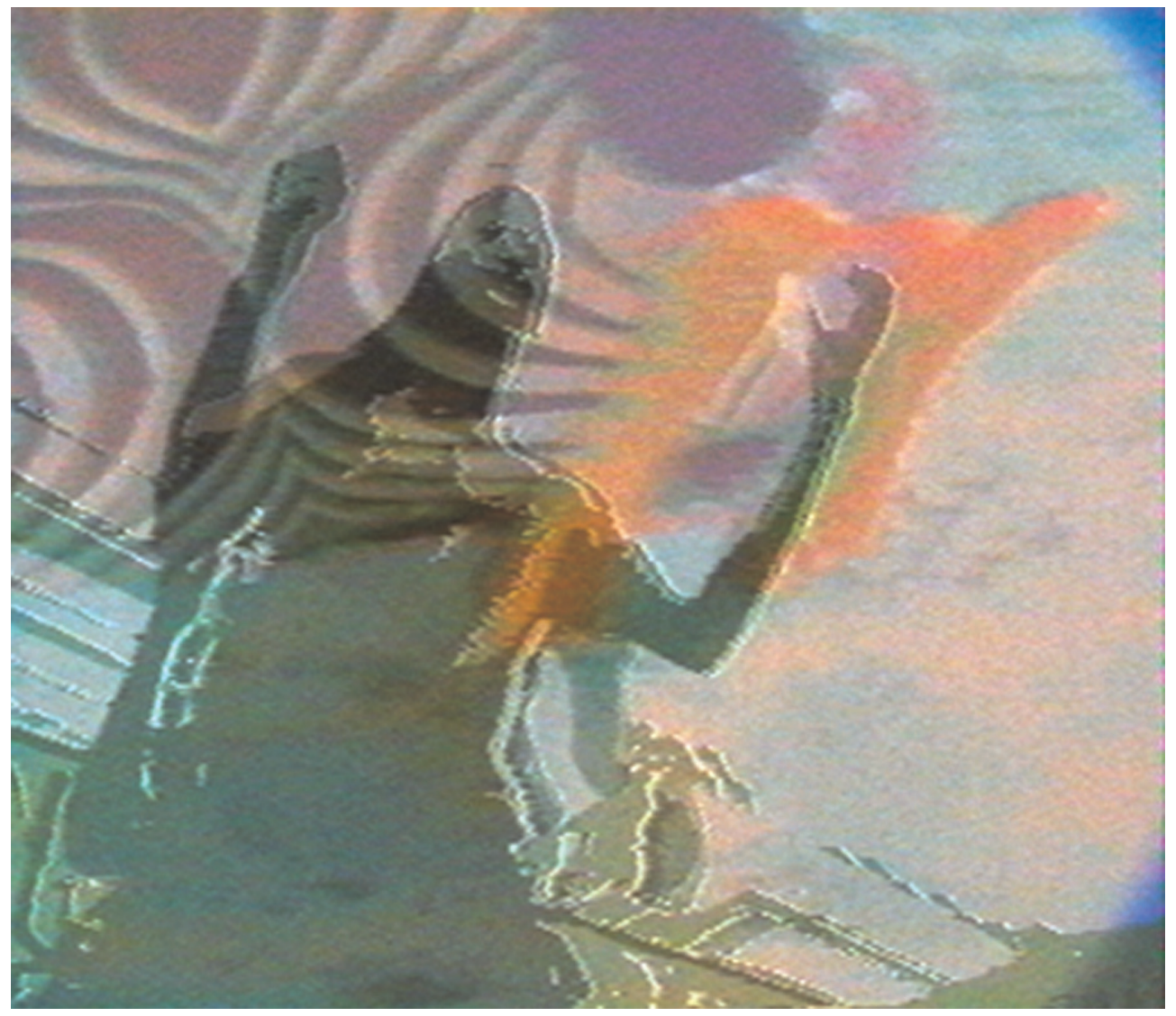

Photo 7. Scratch Free State (dir. George Barber, 1984)

\section{A Third Body}

Alongside the rigid, mechanized bodies of passive consumption, Scratch also offers another body: liquid and malleable, retooled, keyed, and synthesized through the psychedelic alterations of digital image-processing. If Burroughs and Gysin's notion of a 'third mind' sought a unity of two consciousnesses, discrete or unassimilable elements held simultaneously, perhaps Scratch Video, in turn, seeks the image of a third body: a hybrid image stitched tenuously together through keying and cross-cutting, multiple planes of reality in one ambivalent image. ${ }^{21}$

While some Scratch Video works exhibit a paranoia and skepticism toward contemporary image culture, this other mode of Scratch expresses the desire for video to create new possibilities for spectatorship, even for the human sensorium. In this sense, Scratch contributes to the contemporary discourse of posthumanism and the role that movingimage consumption might play in this evolution of human consciousness and form. A video like Barber's Scratch Free State (1984), in which images of technology, pornography, and wildlife bleed into one another, is euphoric, rather than cynical: bodies in the throes of sexual passion or tribal dance morph into snakes, raccoons, and sea mammals, and then into jet-planes or video-game avatars or geometric abstraction, in a delirious, barely distinguishable soup of synthesized imagery. 


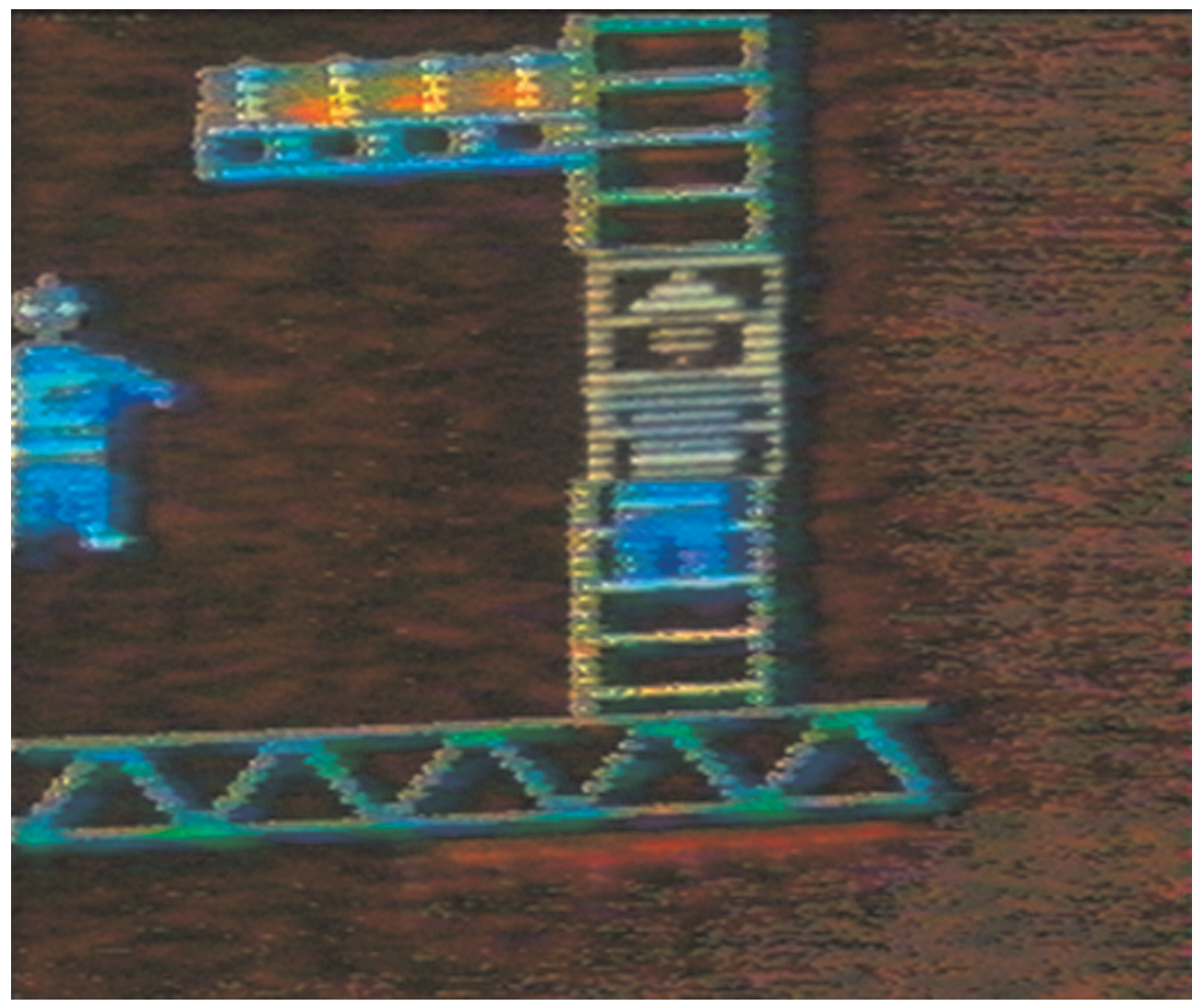

Photo 8. Scratch Free State (dir. George Barber, 1984)

Donna Haraway's then-contemporary figure of the cyborg, with its "transgressed boundaries, potent fusions, and dangerous possibilities," is a useful point of reference here: serving as an index of a set of rapidly dissolving distinctions between human and animal; organic and machine; material and immaterial. ${ }^{22}$ In Barber's work especially, the rigidity of the cut and the loop gives way to the liquid, flowing contours of the image processor, forming a composited, hybrid image that, like Haraway's cyborg, allows us to hold a kind of double vision: conscious, simultaneously, of the video image's pacifying allure and its potential for resistance and rupture.

For all of these contradictions, it is perhaps not surprising that Scratch was short-lived. The kinetic style of Scratch proved enormously appealing to advertisers and music video makers, the composited and heavily keyed and treated video image would soon become a staple of news programs. In turn, consumption and production have themselves become increasingly inextricable, and not always in the euphoric, utopian mode once envisioned: indeed, with the increased ability to quantify our consumption, attention, and affects, our consumption becomes itself a producing form of labor, one that is often more alienated and exploited than interactive and democratic. Technologies of interactivity, media apparatuses that enable a fusing of the roles of the consumer and producer, are themselves ambivalent, and Scratch's unique exploration of these modes of expression and their effect upon (and representation of) the body makes these contradictions explicit and visible. Even so, Scratch Video's aesthetic of appropriation still holds out some uncertainty in this representation, some possibility for counter-reading and alternative strategies. By making visible these paradoxes, Scratch's brief moment of prominence also introduces disruption, distortion, and noise-unassimilable elements that operates against the wholeness and integrity of the image in favour of the contrary, the excessive, and the indigestible. 


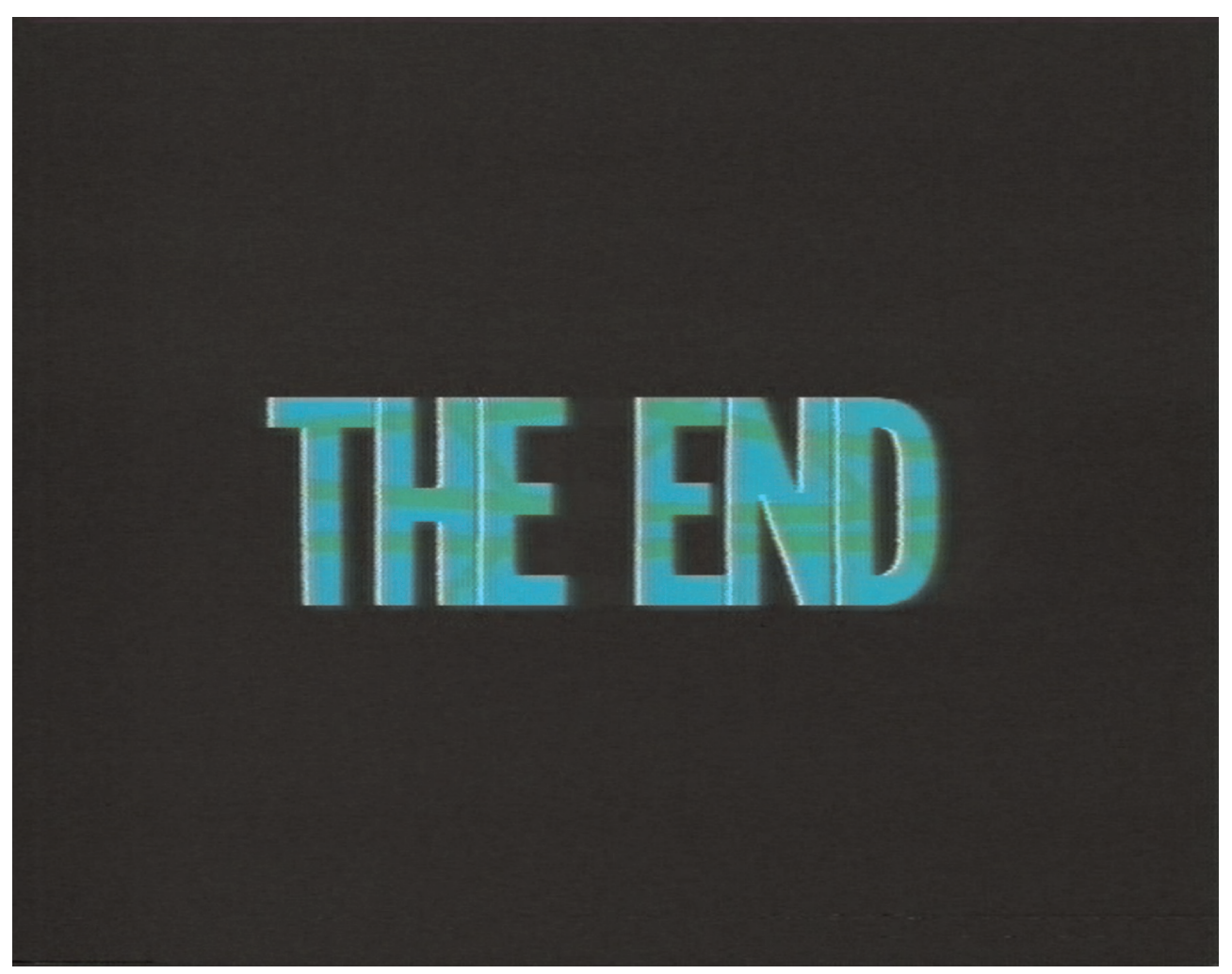

Photo 9. The Greatest Hits of Scratch Video, Vol. 1 (1985)

\section{B i o graph y}

Leo Goldsmith is a PhD Candidate in the Department of Cinema Studies at New York University, where he is completing a dissertation on found footage and image circulation. He is the co-editor of the film section of The Brooklyn Rail, a monthly arts and politics newspaper, and writes on film and media for art-agenda, Artforum, and Cinema Scope. $\mathrm{He}$ is the co-author, with Robert Stam and Richard Porton, of Keywords in Subversive Film/Media Aesthetics (Wiley, 2015), and, with Rachael Rakes, of a forthcoming book on the filmmaker Peter Watkins. He has organized exhibitions and film series for the Museum of the Moving Image, the Ann Arbor Film Festival, UnionDocs, 92Y Tribeca, and the Contemporary Art Centre (Vilnius, Lithuania). 